\title{
EFFECT OF PHYSICAL FATIGUE AND SMOKING CIGARETTES ON THE CPR EFFECTIVENESS PERFORMED BY SOLDIERS
}

\author{
Beata Zysiak-Christ ${ }^{1}{ }^{\circ}$, Joanna Pieczynska ${ }^{2} \oplus$ \\ ${ }^{1}$ Faculty of Security Studies, General Tadeusz Kosciuszko Military University of Land Forces in Wroclaw, Poland \\ ${ }^{2}$ Department of Food Science and Dietetics, Wroclaw Medical University, Wroclaw, Poland
}

\begin{abstract}
INTRODUCTION: The witness of the event plays an important role in the diagnosis of cardiac arrest in the victim. Taking quick actions to restore basic life functions is the essence of pre-hospital assistance, and this applies not only to civilian conditions but also to combat operations. During extraordinary occurrences and civil-military cooperation, the soldier's physical fitness and the ability to perform cardiopulmonary resuscitation effectively give a better chance to save the cardiac arrest victim's life. The study aimed to assess the quality of cardiopulmonary resuscitation (CPR) performed by soldiers before and after physical activity, taking account of smoking by the examined persons.
\end{abstract}

MATERIAL AND METHODS: Fifty-four soldiers took part in the study. The assessment included a 2-minute CPR performance by the soldier before and after physical activity in the Tactical Field Care zone. The Little Anne phantom was used to record CPR quality. Among the examined soldiers, $20 \%$ were active smokers.

RESULTS: The research showed that the average CPR effectiveness before exercise was significantly higher than after combat operations ( $75 \%$ vs. $73 \%$ ). The research also demonstrated that, physical fatigue significantly reduced the rate of chest compressions and the percentage of full chest recoil during CPR. Smoking had no significant effect on the quality of CPR performance. The quality of performance of the CPR components correlated with Body Mass Index (BMI), age, and time since the last training completion.

CONCLUSIONS: The quality of CPR performance after combat exercise is lower than before the physical fatigue. While smoking does not affect CPR performance quality, other factors such as BMI, age, and time since the last training completion are relevant in this context.

KEY WORDS: cardiopulmonary resuscitation, physical fatigue, smoking, soldiers

Disaster Emerg Med J 2021; 6(3): 130-136

\section{INTRODUCTION}

The witness of the event plays an important role in the diagnosis of cardiac arrest in the victim. Taking quick actions to restore basic life functions is the essence of pre-hospital assistance, and this applies not only to civilian conditions but also to combat operations.

The increase in the victim's cardiac arrest survival rate is determined by starting cardiopulmonary resuscitation (CPR) as soon as possible. 
According to the European Resuscitation Council (ERC), the highest effectiveness of resuscitation is influenced by the correct depth, frequency, and quality of compressions. Equally important is the appropriate amount of air forced until the chest rises noticeably, as well as the shortest possible intervals between compressions and ventilation and the lack of prolongation of ventilation [1]. CPR, especially if administered immediately after cardiac arrest, can double or triple a person's chance of survival. Therefore, the authors point to the essence of almost immediate cardiopulmonary resuscitation in pre-hospital conditions as an important aspect of survival in people in cardiac arrest $[2,6]$.

The algorithms, which include but are not limited to civil medicine, determine that the sequence and importance of procedures play a significant role in the effectiveness of rescue operations. These algorithms are developed by various institutions among which are the International Liaison Committee on Resuscitation and ERC $[1,7]$. Also, the first aid procedure performed by persons without medical qualifications should be based on the latest guidelines which are clearly defined.

Military medicine is developing as dynamically as civil medicine. Its advancement concerns both procedures and algorithms of the procedure.

The Tactical Combat Casualty Care Committee defined the standards of conduct in the tactical environment for soldiers, which were first implemented in 1996. These standards include the rules of dealing with the injured in combat conditions. This procedure depends both on the external environment and the type of victim's injuries. The purpose of these standards is to reduce the number of preventable deaths on the battlefield. According to the assumptions of tactical medicine, CPR can be performed in the field phase of care for the injured, as long as the casualty has not suffered fatal wounds [8,9].

Despite the different priorities between civil and military rescue, it is not about who will perform CPR, but whether it is effective. Civil-military cooperation is an indispensable element to increase the effectiveness of rescue operations.

The Armed Forces take part in combating natural disasters, eliminating their effects, activities in the field of property, search and rescue operations, in which the essence is saving life and health. Being able to perform CPR is one of the essential aspects of providing aid. Therefore, it can be concluded that this is one of the biggest priorities among the tasks carried out in rescue operations performed in both civil and military environments.

Rescue operations often occur during extraordinary events; hence, their speed and efficiency are decisive for action success. During extraordinary occurrences and civil-military cooperation, the soldier's physical fitness and the ability to perform cardiopulmonary resuscitation effectively give a better chance to save the cardiac arrest victim's life.

To our knowledge, no studies have been conducted so far that would determine the quality of CPR performance by a soldier, especially after completed activities in the Care Under Fire zone and the evacuation of the victim to the Tactical Field Care zone. Such studies are also extremely rare among civilian rescue services.

This study aimed to assess the CPR quality carried out by soldiers before and after operations in the danger zone, taking into consideration their smoking habits.

\section{MATERIAL AND METHODS}

\section{Study group}

Fifty-four soldiers from the Military University of Land Forces in Wroclaw participated in the research. As an inclusion criterion in the study for the soldiers was a first aid course, including resuscitation exercises or qualified first aid courses completed within the last three years.

\section{Study design}

The Little Anne manikin connected with the Laerdal PC SkillReporting software (Laerdal, Norway) was used as a research tool to assess the quality of CPR performance, allowing for the recording of all quality parameters such as CPR effectiveness, chest compression rate, full chest recoil, and chest compression and ventilation fraction.

The enrolled soldiers also completed a questionnaire providing information about their age, military rank, height, body weight, smoking, and time since the last first aid training data. The resting heart rate and heart rate after physical effort were measured using a Sanitas heart rate monitor.

The tests were performed before and after physical exertion. After completing the questionnaire and measuring the heart rate while resting during classes, participants started performing CPR on the manikin for the duration of 2 minutes. 


\begin{tabular}{|l|c|c|c|}
\hline & Table 1. Characteristics of the study group by smoking status, median (min-max) & Non-smokers \\
& $\begin{array}{c}\text { Active smokers } \\
\mathrm{n}=11\end{array}$ & $27(24-33)$ & $\mathrm{p}$ \\
\hline Age $[$ years] & $27(25-30)$ & $23.75(19.87-25.92)$ & $\mathrm{NS}$ \\
\hline $\mathrm{BMI}\left[\mathrm{m}^{2} / \mathrm{kg}\right]$ & $23.70(22.94-26.54)$ & $7(4-36)$ & $\mathrm{NS}$ \\
\hline Time since the last training [months] & $7(2-8)$ & $62(54-78)$ & 0.012 \\
\hline Resting heart rate [beats/min] & $67(61-73)$ & $163(128-184)$ & 0.021 \\
\hline Heart rate after effort [beats/min] & $171(156-183)$ & & \\
\hline
\end{tabular}

$\mathrm{p} \leq 0.05 ; \mathrm{BMI}$ - Body Mass Index

Table 2. Comparison of the cardiopulmonary resuscitation quality parameters before and after physical activity,
median (min-max)
\begin{tabular}{|l|c|c|c|}
\hline Parameter & $\begin{array}{c}\text { Values before the physical activity } \\
\mathrm{n}=54\end{array}$ & $\begin{array}{c}\text { Values after the physical activity } \\
\mathrm{n}=54\end{array}$ & $\mathrm{p}$ \\
\hline CPR effectiveness [\%] & $75(29-94)$ & $73(13-98)$ & 0.015 \\
\hline Chest compression fraction [\%] & $71.5(20-87)$ & $72.5(25-88)$ & NS \\
\hline Chest compression rate [n/min] & $119(100-134)$ & $119.5(102-136)$ & 0.001 \\
\hline Full chest recoil [\%] & $33(3-99)$ & $31(5-99)$ & 0.005 \\
\hline Ventilation fraction [\%] & $76(21-100)$ & $76(34-100)$ & NS \\
\hline
\end{tabular}

$p \leq 0.05$; CPR - cardiopulmonary resuscitation

The same group of soldiers had combat operations during tactical exercises at the training ground a few days later. After the actions carried out in the Care Under Fire zone, i.e., securing a hemorrhage from an injury to the lower limb using the Combat Application Tourniquet (CAT), the four-soldier groups were tasked to evacuate the injured person on mesh stretchers as rapidly as possible to the Tactical Field Care zone. Each of the teams had a 200-meter distance to cover as part of the evacuation, in a grass-sand training ground. After arriving at the Tactical Field Care zone, the soldiers' heart rate was measured and they started to perform a 2-minute cardiopulmonary resuscitation on the manikin.

Ethical approval was obtained from the Military University of Land Forces in Wroclaw review board (approval number 149/WNB/68/DzS).

\section{Statistical analysis}

The result distribution normality was estimated using the Kolmogorov-Smirnov test; the non-parametric Mann-Whitney $U$ test was applied to analyze the findings in the groups of independent variables and the Wilcoxon paired test was used for the group of dependent variables. Spearman's rank correlations were used to assess the relationships. The statistical analysis was performed with the Statistica v. 13 program.

\section{RESULTS}

Table 1 shows the characteristics of the study group, taking their smoking habits into account. Only 20\% of the surveyed soldiers declared smoking. The average age in both groups was 27 years, while Body Mass Index (BMI) oscillated around the upper limit of normal $-23 \mathrm{~kg} / \mathrm{m}^{2}$. The vast majority of the surveyed soldiers underwent first aid training six months before the tests.

The heart rate was statistically significantly lower both before and after exercising in non-smokers compared to smokers.

Table 2 compares the CPR quality parameters before and after the physical fatigue in the study group. Effort during tactical operations significantly reduced the CPR effectiveness and full chest recoil as well as increased the rate of chest compressions compared to the results before physical effort. The average rates of chest compressions both before and after the physical activity fell within the ERC's quantitative standards. For the other assessed parameters, post-combat exercise did not affect the results. 
Table 3. Comparison of the cardiopulmonary resuscitation quality parameters before and after physical activity depending on smoking status, median (min-max)

\begin{tabular}{|c|c|c|c|}
\hline & $\begin{array}{c}\text { Smokers } \\
\mathrm{n}=11\end{array}$ & $\begin{array}{c}\text { Non-smokers } \\
n=43\end{array}$ & $p$ \\
\hline \multicolumn{4}{|c|}{ CPR effectiveness [\%] } \\
\hline Before effort & $75(32-93)$ & $75(29-94)$ & NS \\
\hline After effort & $75(30-98)$ & $71(13-90)$ & NS \\
\hline \multicolumn{4}{|c|}{ Chest compression fraction [\%] } \\
\hline Before effort & $71(52-81)$ & $72(20-87)$ & NS \\
\hline After effort & $76(62-82)$ & $72(25-88)$ & NS \\
\hline \multicolumn{4}{|c|}{ Chest compression rate [n/min] } \\
\hline Before effort & $120(100-134)$ & $118(104-132)$ & NS \\
\hline After effort & $121(102-136)$ & $119(105-132)$ & NS \\
\hline \multicolumn{4}{|c|}{ Full chest recoil [\%] } \\
\hline Before effort & $30(16-89)$ & $34(3-99)$ & NS \\
\hline After effort & $30(14-83)$ & $31(5-99)$ & NS \\
\hline \multicolumn{4}{|c|}{ Ventilation fraction [\%] } \\
\hline Before effort & $78(59-91)$ & $75(21-100)$ & NS \\
\hline After effort & $81(71-100)$ & $75(34-100)$ & NS \\
\hline
\end{tabular}

Table 3 compares the CPR quality parameters before and after effort, depending on smoking habit. Besides the percentage of full chest recoil, lower values of the assessed CPR quality parameters were observed in the group of non-smoking soldiers than in the smokers' group. However, the observed differences were not statistically significant.

The statistical analysis (Tab. 4) showed a significant negative correlation between the CPR effectiveness before the effort and time since the last training, and a positive correlation of full chest recoil rate and the ventilation fraction before effort with BMI. After the effort, only BMI positively correlated with the ventilation fraction. The strong positive correlation between the average rate of chest compressions and the examined soldiers' age was observed only among smokers.

\section{DISCUSSION}

Cardiac arrest is one of the leading causes of death worldwide $[10,11]$. The out-of-hospital sudden cardiac death affects a large number of victims in Poland. According to the latest studies, in 2018 a total of 26,783 CPR attempts were performed in pre-hospital conditions [12]. In many countries, for several years, the emphasis has been placed on training that includes the ability to perform effective CPR both among medical staff and non-medical witnesses of the event $[6,13-15]$.

Research results indicate that the optimization of procedures plays a key role in saving the lives of patients who have had a cardiac arrest [11]. The importance and impact of the quality of CPR and its parameters on the survival of patients are also emphasized [16-19].

The few studies conducted so far indicate that firefighters and police officers can carry out effective CPR $[20,21]$. The lack of evaluation of soldier-led CPR effectiveness in the current scientific studies indicates a gap in this research area and the need to explore the subject. Every soldier should be skilled at successfully performing CPR.

The presented study focuses on the assessment of CPR effectiveness, inter alia, because in a situation where resuscitation is possible, the soldier should undertake it. They should also use these skills during civil rescue operations. In the available studies, the authors present many proposals for assessing the CPR quality, but so far no single, universal, and widely accepted indicator of the quality of resuscitation has not been developed and applied [22]. In the present study, the common parameters such as chest compression rate, full chest recoil, and chest 


\begin{tabular}{|c|c|c|}
\hline & $\mathrm{R}$ & $\mathrm{p}$ \\
\hline \multicolumn{3}{|c|}{ Before effort - all study participants $(n=54)$} \\
\hline CPR effectiveness vs. time since the last training & -0.28 & 0.041 \\
\hline Full chest recoil vs. BMI & 0.32 & 0.018 \\
\hline Ventilation fraction vs. BMI & 0.30 & 0.029 \\
\hline \multicolumn{3}{|c|}{ After effort - all study participants $(n=54)$} \\
\hline Full chest recoil vs. BMI & 0.32 & 0.020 \\
\hline \multicolumn{3}{|c|}{ Before effort - smokers $(n=11)$} \\
\hline Chest compressions rate vs. age & 0.65 & 0.030 \\
\hline
\end{tabular}

$\mathrm{p} \leq 0.05$; CPR — cardiopulmonary resuscitation; BMI - Body Mass Index

compression and ventilation fraction were used to assess the CPR quality.

Before physical exertion, the values of CPR qualitative parameters in the surveyed soldiers were very similar to those obtained by medical staff concerning full chest recoil, chest compression fraction, and chest compression rate, however, it should be noted that the studies differed in the length of time conducting CPR [23-27].

Physical effort during combat operations significantly decreased both the effectiveness of CPR and the percentage of full chest recoil and caused an increase in the number of chest compressions among the examined soldiers (Tab. 2). Similar results are presented in the study by Barcal-Furelos et al. [28], where the lifeguards' CPR effectiveness before and after the rescue operation was assessed. Other studies have also shown a significant effect of physical performance on the quality and duration of CPR [29]. However, our research did not show significant differences between the quality of compressions or rescue breaths performed before exercise versus those after combat operations. Both parameters were within the ranges of effectiveness, although their level was not the highest.

In the assumption of our study, the smoking habit was selected as a factor that may affect the effectiveness of CPR. Statistical analysis of the obtained results showed that smoking did not affect the CPR quality and effectiveness (Tab. 3). The reason for such observation may be the fact that the study was conducted on a group of age-homogeneous young men, whose smoking had not yet had an impact on the physical performance or the possible changes were masked by regular aerobic and anaerobic training. However, observations published by other authors in- dicate that the smoking habit in young men reduces the results achieved in physical fitness tests [30-32]. Even though smoking did not affect the CPR effectiveness, the heart rate was significantly lower in the non-smoking group compared to smokers, both at rest and after physical effort (Tab. 1). Other authors obtained similar observations, although their research was conducted only during the rest [33].

Chest compressions are an important part of life-saving activities, especially when defibrillation is impossible [34]. The conducted research shows that the Body Mass Index (BMI) value positively correlated with the percentage of complete compressions both during resting and after exercising (Tab. 4). Hong et al. [35] presented similar findings where overweight or obese subjects (BMI above $25 \mathrm{~kg} / \mathrm{m} 2$ ) had better compression quality. Almost all our study participants had normal BMI and a high level of physical fitness as a result of regular strength exercises (unpublished data). Similarly, other authors' studies have shown that strength training benefits CPR effectiveness [36, 37].

The results of our study indicate that the smoking soldiers' age was positively correlated with the average number of compressions (Tab. 4). Hong et al. [35] in their study also found a relationship between the age of the person performing CPR and the effectiveness of compressions. The statistical analysis of the obtained results also showed a negative correlation between the time that has passed since the last training and the effectiveness of CPR (Tab. 4). The results of our research coincide with the observations of other authors who indicate that the quality and effectiveness of CPR depends on factors such as training, fatigue, technique, and awareness [38]. 
It seems that there is a need to practice CPR more often than one phantom training seven month ago, which will allow the development of muscle memory that affects the quality of CPR performance in real activities. As the results of our research show, a soldier performing operations in combat conditions can effectively carry out CPR, even if CPR is performed after activities that increase fatigue. To our knowledge, the authors' pilot study is the first observation made on this topic. In the author's opinion, it is necessary to continue the research with the participation of a larger number of soldiers and an extended range of parameters (varied weather conditions, different topography). Thanks to this, it will be possible to identify elements of CPR training that require the special commitment of the student to achieve maximum CPR effectiveness.

\section{Limitations of the study}

The conducted study has several limitations. The study group was relatively small and consisted only of men in a narrow age range, which could have impacted the results obtained. Likewise, information on the number of cigarettes smoked per day and the smoking period length could refine the obtained data.

\section{CONCLUSIONS}

The effectiveness of CPR after exercise under combat conditions decreases compared to conditions that do not require physical effort. The quality of CPR performance is influenced by factors such as $\mathrm{BMI}$, age, and time since last training, but not by smoking habits.

\section{REFERENCES}

1. Perkins GD, Olasveengen TM, Maconochie I, et al. European Resuscitation Council. European Resuscitation Council Guidelines for Resuscitation: 2017 update. Resuscitation. 2018; 123: 43-50, doi: 10.1016/j.resuscitation.2017.12.007, indexed in Pubmed: 29233740.

2. Waalewijn R, Tijssen J, Koster R. Bystander initiated actions in out-of-hospital cardiopulmonary resuscitation: results from the Amsterdam Resuscitation Study (ARRESUST). Resuscitation. 2001; 50(3): 273-279, doi: 10.1016/50300-9572(01)00354-9.

3. Wissenberg M, Lippert FK, Folke F, et al. Association of national initiatives to improve cardiac arrest management with rates of bystander intervention and patient survival after out-of-hospital cardiac arrest. JAMA. 2013; 310(13): 1377-1384, doi: 10.1001/jama.2013.278483, indexed in Pubmed: 24084923.
4. Hasselqvist-Ax I, Riva G, Herlitz J, et al. Early cardiopulmonary resuscitation in out-of-hospital cardiac arrest. N Engl J Med. 2015; 372(24): 2307-2315, doi: 10.1056/NEJMoa1405796, indexed in Pubmed: 26061835.

5. Ertl L, Christ F. Significant improvement of the quality of bystander first aid using an expert system with a mobile multimedia device. Resuscitation. 2007; 74(2): 286-295, doi: 10.1016/j.resuscitation.2007.01.006, indexed in Pubmed: 17376581.

6. Perry $M$. The importance of CPR/AED and first aid training for security officers and SROs. Handbook of Loss Prevention and Crime Prevention. 2020: 449-453, doi: 10.1016/b978-0-12-817273-5.00038-7.

7. Soar J, Maconochie I, Wyckoff MH, et al. 2019 International Consensus on Cardiopulmonary Resuscitation and Emergency Cardiovascular Care Science With Treatment Recommendations: Summary From the Basic Life Support; Advanced Life Support; Pediatric Life Support; Neonatal Life Support; Education, Implementation, and Teams; and First Aid Task Forces. Circulation. 2019; 140(24): e826-e880, doi: 10.1161/ CIR.0000000000000734, indexed in Pubmed: 31722543.

8. Butler FK, Holcomb JB, Shackelford S, et al. Advanced Resuscitative Care in Tactical Combat Casualty Care: TCCC Guidelines Change 1801:14 October 2018. J Spec Oper Med. 2018; 18(4): 37-55, indexed in Pubmed: 30566723.

9. Montgomery HR, Butler FK, Kerr W, et al. TCCC Guidelines Comprehensive Review and Update: TCCC Guidelines Change 16-03. J Spec Oper Med. 2017; 17(2): 21-38, indexed in Pubmed: 28599032.

10. Fugate J, Brinjikji W, Mandrekar J, et al. Post-Cardiac Arrest Mortality Is Declining. Circulation. 2012; 126(5): 546-550, doi: 10.1161/ circulationaha.111.088807.

11. Jalali A, Berg RA, Nadkarni $V$, et al. Model based optimization of the cardiopulmonary resuscitation (CPR) procedure. Annu Int Conf IEEE Eng Med Biol Soc. 2012; 2012: 715-718, doi: 10.1109/ EMBC.2012.6346031, indexed in Pubmed: 23365992.

12. Świeżewski S, Rabczenko D, Wejnarski A, et al. UTILIZATION OF AIR SUPPORT IN THE POLISH EMERGENCY MEDICAL SYSTE M FOR PATIENTS WITH OUT-OF-HOSPITAL CARDIAC ARREST. Emergency Medical Service. 2020; 7(4): 247-255, doi: 10.36740/emems202004101.

13. Mokhtari Nori J, Saghafinia M, Kalantar Motamedi MH, et al. CPR Training for Nurses: How often Is It Necessary? Iran Red Crescent Med J. 2012; 14(2): 104-107, indexed in Pubmed: 22737563.

14. Winkelman JL, Fischbach R, Spinello EF. Assessing CPR Training: The willingness of teaching credential candidates to provide CPR in a school setting. Educ Health. 2009; 22(3): 81-92.

15. Semeraro F, Taggi F, Tammaro G, et al. iCPR: a new application of high-quality cardiopulmonary resuscitation training. Resuscitation. 2011; 82(4): 436-441, doi: 10.1016/j.resuscitation.2010.11.023, indexed in Pubmed: 21227560.

16. Jalali A, Simpao AF, Gálvez JA, et al. A Dynamic Model of Rescuer Parameters for Optimizing Blood Gas Delivery during Cardiopulmonary Resuscitation. Comput Math Methods Med. 2018; 2018: 3569346, doi: 10.1155/2018/3569346, indexed in Pubmed: 30687409. 
17. Cha KC, Kim YW, Kim TH, et al. Comparison Between 30:1 and 30:2 Compression-to-ventilation Ratios for Cardiopulmonary Resuscitation: Are Two Ventilations Necessary? Acad Emerg Med. 2015; 22(11): 1261-1266, doi: 10.1111/acem. 12796, indexed in Pubmed: 26470011.

18. Yeh S, Cawley R, Aune $S$, et al. Oxygen requirement during cardiopulmonary resuscitation (CPR) to effect return of spontaneous circulation. Resuscitation. 2009; 80(8): 951-955, doi: 10.1016/j. resuscitation.2009.05.001.

19. Wik L, Steen PA, Bircher NG. Quality of bystander cardiopulmonary resuscitation influences outcome after prehospital cardiac arrest. Resuscitation. 1994; 28(3): 195-203, doi: 10.1016/0300-9572(94)90064-7, indexed in Pubmed: 7740189.

20. Olasveengen TM, Wik L, Kramer-Johansen Jo, et al. Quality of cardiopulmonary resuscitation during out-of-hospital cardiac arrest. JAMA. 2005; 293(3): 299-304, doi: 10.1001/jama.293.3.299, indexed in Pubmed: 15657322.

21. Szarpak L, Smereka J, Madziala M, et al. Impact of the newly mechanical chest compression machine LifeLine ARM in contrast to standard BLS performed by firefighters. Resuscitation. 2016; 106: e20, doi: 10.1016/j.resuscitation.2016.07.046.

22. Kłosiewicz T, Puślecki M, Zalewski R, et al. Assessment of Chest Compression Quality - a systematic review. Disaster and Emergency Medicine Journal. 2020; 5(1): 49-56, doi: 10.5603/demj. a2020.0010.

23. Majer J, Jaguszewski MJ, Frass M, et al. Does the use of cardiopulmonary resuscitation feedback devices improve the quality of chest compressions performed by doctors? A prospective, randomized, cross-over simulation study. Cardiol J. 2019; 26(5): 529-535, doi: 10.5603/CJ.a2018.0091, indexed in Pubmed: 30155865.

24. Smereka J, Szarpak L, Czekajlo M, et al. The TrueCPR device in the process of teaching cardiopulmonary resuscitation: A randomized simulation trial. Medicine (Baltimore). 2019; 98(27): e15995, doi: 10.1097/MD.0000000000015995, indexed in Pubmed: 31277091.

25. Kłosiewicz T, Puślecki M, Zalewski $R$, et al. Analysis of the quality of chest compressions during resuscitation in an understaffed team - randomised crossover manikin study. Disaster and Emergency Medicine Journal. 2020; 5(1): 24-29, doi: 10.5603/demj.a2020.0008.

26. Jorge-Soto C, Abilleira-González M, Otero-Agra M, et al. Schoolteachers as candidates to be basic life support trainers: A simulation trial. Cardiol J. 2019; 26(5): 536-542, doi: 10.5603/CJ.a2018.0073, indexed in Pubmed: 30009374.

27. Truszewski Z, Szarpak L, Kurowski A, et al. Randomized trial of the chest compressions effectiveness comparing 3 feedback CPR devices and standard basic life support by nurses. Am J Emerg Med. 2016; 34(3): 381-385, doi: 10.1016/j.ajem.2015.11.003, indexed in Pubmed: 26612703.
28. Barcala-Furelos R, Abelairas-Gomez C, Romo-Perez V, et al. Effect of physical fatigue on the quality CPR: a water rescue study of lifeguards: physical fatigue and quality CPR in a water rescue. Am J Emerg Med. 2013; 31(3): 473-477, doi: 10.1016/j.ajem.2012.09.012, indexed in Pubmed: 23085007.

29. Lucía $A$, de las Heras JF, Pérez $M$, et al. The importance of physical fitness in the performance of adequate cardiopulmonary resuscitation. Chest. 1999; 115(1): 158-164, doi: 10.1378/chest.115.1.158, indexed in Pubmed: 9925078.

30. Hawari FI, Obeidat NA, Ghonimat IM, et al. The effect of habitual waterpipe tobacco smoking on pulmonary function and exercise capacity in young healthy males: A pilot study. Respir Med. 2017; 122: 71-75, doi: 10.1016/j.rmed.2016.11.024, indexed in Pubmed: 27993294.

31. Bird $Y$, Staines-Orozco H. Pulmonary effects of active smoking and secondhand smoke exposure among adolescent students in Juárez, Mexico. Int J Chron Obstruct Pulmon Dis. 2016; 11: 1459-1467, doi: 10.2147/COPD.S102999, indexed in Pubmed: 27418819.

32. Elbehairy AF, Faisal A, Guenette JA, et al. Canadian Respiratory Research Network (CRRN). Resting Physiological Correlates of Reduced Exercise Capacity in Smokers with Mild Airway Obstruction. COPD. 2017; 14(3): 267-275, doi: 10.1080/15412555.2017.1281901, indexed in Pubmed: 28368706.

33. Hieshima K, Suzuki T, Sugiyama S, et al. Smoking Cessation Ameliorates Microalbuminuria With Reduction of Blood Pressure and Pulse Rate in Patients With Already Diagnosed Diabetes Mellitus. J Clin Med Res. 2018; 10(6): 478-485, doi: 10.14740/jocmr3400w, indexed in Pubmed: 29707089.

34. Butcher BW, Quist CE, Harrison JD, et al. The effect of a rapid response team on resident perceptions of education and autonomy. J Hosp Med. 2015; 10(1): 8-12, doi: 10.1002/jhm.2270, indexed in Pubmed: 25603788.

35. Hong DY, Park SO, Lee KR, et al. A different rescuer changing strategy between 30:2 cardiopulmonary resuscitation and hands-only cardiopulmonary resuscitation that considers rescuer factors: a randomised cross-over simulation study with a time-dependent analysis. Resuscitation. 2012; 83(3): 353-359, doi: 10.1016/j.resuscitation.2011.11.006, indexed in Pubmed: 22101200.

36. Sayee N, McCluskey D. Factors influencing performance of cardiopulmonary resuscitation (CPR) by Foundation Year 1 hospital doctors. Ulster Med J. 2012; 81(1): 14-18, indexed in Pubmed: 23536733.

37. Abelairas-Gómez C, Barcala-Furelos R, Szarpak $\iota$, et al. The effect of strength training on quality of prolonged basic cardiopulmonary resuscitation. Kardiol Pol. 2017; 75(1): 21-27, doi: 10.5603/KP.a2016.0165, indexed in Pubmed: 27878801.

38. Radha R. Improving the quality of CPR in the Community. International Journal of Nursing Education and Research. 2020; 8(1): 135, doi: 10.5958/2454-2660.2020.00031.9. 